\title{
Karakteristik Ruang pada Rumah Tradisional Tanean Lanjhang di Desa Bandang Laok, Kecamatan Kokop, Kabupaten Bangkalan, Madura
}

\author{
Widya Aprilia Kurnia, Agung Murti Nugroho \\ Program Magister Arsitektur Lingkungan Binaan \\ Fakultas Teknik, Universitas Brawijaya Malang \\ wapriliak@yahoo.com,sasimurti@yahoo.co.id
}

\begin{abstract}
ABSTRAK
Tanean Lanjhang merupakan bentuk rumah tradisional Madura yang memiliki komponenkomponen yang di antaranya adalah Langghar (Musholla), rumah utama yang diikuti rumahrumah lainnya yang pada umumnya berderet dari Barat ke Timur, sesuai dengan urutan dalam keluarga, dapur, kandang, dan Tanean (pekarangan). Pada penelitian ini dibahas tentang karakteristik ruang pada rumah tradisional Tanean Lanjhang di Desa Bandang Laok, Kecamatan Kokop, Kabupaten Bangkalan, Madura yang terfokus pada beberapa kelompok Tanean Lanjhang di Dusun Baktalbak. Metode yang digunakan dalam penelitian ini adalah deskriptif kualitatif dengan menganalisis hasil identifikasi karakteristik ruang pada masingmasing kelompok Tanean. Hasil penelitian menunjukkan bahwa pola Tanean Lanjhang yang hanya terdapat 1 rumah utama saja disebabkan oleh keterbatasan lahan untuk mendirikan rumah hunian baru, sehingga keluarga baru/muda harus membuat rumah hunian lain dengan pola Tanean Lanjhang juga. Selain itu terdapat persamaan bentuk ruang dengan ukuran ruang yang bervariasi, sesuai dengan fungsi dan kegunaan. Sementara itu, perbedaan pembatas ruang dan komponen ruang menunjukkan tingkat perekonomian yang berbeda.
\end{abstract}

Kata Kunci: rumah tradisional, Tanean Lanjhang, karakteristik Ruang.

\begin{abstract}
Tanean Lanjhang is a form of Madurese traditional house which have components of Langghar (mosque), the main house followed by other homes that are generally rows from West to East, according to the order in the family, kitchen, stables, and Tanean (yard). This study discussed about the characteristics of space in a traditional house Tanean Lanjhang in the village of Bandang Laok, Kokop District, Bangkalan Regency, Madura, which focused on several groups of Tanean Lanjhang in Baktalbak village. The method used in this research is descriptive qualitative by analyzing space characteristics on each Tanean group. The results showed that the pattern of Tanean Lanjhang with one main house was caused by the limitation of land to build a new residential house, so the new family must build another residential house with Lanjhang Tanean pattern also. In addition, there is a similarity of form of space with room sizes in vary according to the functionality and usability. While the difference of space barrier and space components showed the different levels of the economy.
\end{abstract}

Keywords: traditional houses, Tanean Lanjhang, characteristics of space. 


\section{Pendahuluan}

Manusia dan kebudayaan merupakan dua hal yang sangat erat berkaitan satu sama lain. Dalam sosiologi manusia dan kebudayaan dinilai sebagai dwitunggal, maksudnya bahwa walaupun keduanya berbeda tetapi keduanya merupakan satu kesatuan. Manusia menciptakan kebudayaan, dan setelah kebudayaan itu tercipta maka kebudayaan mengatur hidup manusia agar sesuai dengannya. Dengan demikian dapat dikatakan bahwa manusia tidak dapat dilepaskan dari kebudayaan, karena kebudayaan itu merupakan perwujudan dari manusia itu sendiri.

Rapoport (1969), mengungkapkan bahwa rumah ditentukan oleh nilai-nilai budaya, iklim, dan kebutuhan akan perlindungan, ekonomi, karakter tapak dan agama. Begitu juga yang terbentuk pada pola pemanfaatan ruang rumah tradisional Madura. Kondisi alam yang panas dan keras ditambah lagi nilai-nilai budaya tradisional Madura telah membentuk pola ruang lingkungan dan hunian rumah tradisional Madura yang spesifik. Rumah sendiri merupakan perwujudan budaya menghuni yang memberi arti hidup dan keletakan posisi pribadinya di lingkungan masyarakat yang membuat manusia mengenal dirinya sebagai makhluk sosial. Konsekuensinya adalah rumah mempunyai potensi sebagai sarana untuk mengaktualisasi diri secara pribadi-privat maupun secara sosialpublik.

Lefebvre (1991:26) berpendapat bahwa ruang adalah produk sosial, berdasarkan nilai-nilai maupun pemaknaan sosial. Dengan kata lain, masyarakat (society) membentuk ruang dengan nilai-nilai dan pemaknaan tadi. Selanjutnya Lefebvre berargumen bahwa setiap masyarakat memiliki cara sendiri dalam memproduksi ruang, dan ruang yang terjadi yang cocok dengan keadaan masyarakat tersebut. Bagaimana jika sebuah eksistensi sosial, yang mengklaim keberadaannya, memproduksi ruang yang tidak sesuai dengan masyarakatnya. Akan menjadi sebuah entitas yang janggal dan tidak akan bermakna ketika ruang yang tercipta tidak sesuai dengan masyarakat.

Pola penataan ruang dalam rumah dalam kaitannya dengan kehidupan sehari-hari begitu sangat penting, terutama di Desa Bandhang, Kecamatan Kokop, Kabupaten Bangkalan, Madura. Pengaruh budaya Madura, terutama dengan pola Tanean Lanjhang yang sudah banyak dikenal, sangat terlihat dalam pola penataan ruang dalam rumah. Sebagian pola Tanean Lanjhang di Desa Bandhang tidak terlihat sebagaimana pola pada umumnya, dimana di Desa tersebut 1 (satu) Tanean (pekarangan) hanya terdiri dari 1 (satu) rumah yang dihuni 1 (satu) keluarga saja.

Tujuan dari penelitin ini adalah untuk: (1) Mengetahui pola Tanean Lanjhang di Desa Bandhang Laok, Kokop, Bangkalan, Madura; (2) Mengetahui dan menganalisis karakteristik ruang pada Tanean Lanjhang di Desa Bandhang Laok, Kokop, Bangkalan, Madura.

\section{Kajian Teori}

Permukiman tradisional Madura adalah suatu kumpulan rumah yang terdiri atas keluarga-keluarga yang mengikatnya. Letaknya sangat berdekatan dengan lahan garapan, mata air atau sungai. Antara permukiman dengan lahan garapan hanya dibatasi tanaman hidup atau peninggian tanah yang disebut galengan atau tabun, sehingga masingmasing kelompok menjadi terpisah oleh lahan garapannya. Satu kelompok rumah terdiri atas 2 sampai 10 rumah, atau dihuni sepuluh keluarga yaitu keluarga batih yang terdiri dari orang tua, anak, cucu, cicit dan seterusnya. Jadi hubungan keluarga kandung merupakan ciri khas dari kelompok ini (Departemen Pendidikan dan Kebudayaan, 1982)

Susunan rumah disusun berdasarkan hirarki dalam keluarga. Barat-timur adalah arah yang menunjukan urutan tua muda. Sistem yang demikian mengakibatkan ikatan kekeluargaan menjadi sangat erat. Sedangkan hubungan antar kelompok sangat renggang karena letak permukiman yang menyebar dan terpisah. Ketergantungan keluarga 
tertentu pada lahan masing masing. Di ujung paling barat terletak langgar. Bagian utara merupakan kelompok rumah yang tersusun sesuai hirarki keluarga. Susunan barat-timur terletak rumah orang tua, anak-anak, cucu- cucu, dan cicit-cicit dari keturunan perempuan. Kelompok keluarga yang demikian yang disebut koren atau rumpun bambu. Istilah ini sangat cocok karena satu koren berarti satu keluarga inti.

Garis keturunan masyarakatnya adalah matrilineal. Hal ini tampak pada tata atur dan kepemilikan rumah, meskipun saat ini mereka menganut extended family. Rumah identik perempuan dan dimiliki bersama, artinya perempuan adalah pemilik sekaligus pemakai rumah tetapi suatu saat pemakaian rumah bisa berpindah saat seniornya yang meninggal dan yang muda akan menempati rumah yang lebih tua. Senior berkewajiban terhadap kesejahteraan juniornya, lebih khusus bagi junior perempuan (Lintu: 2005).

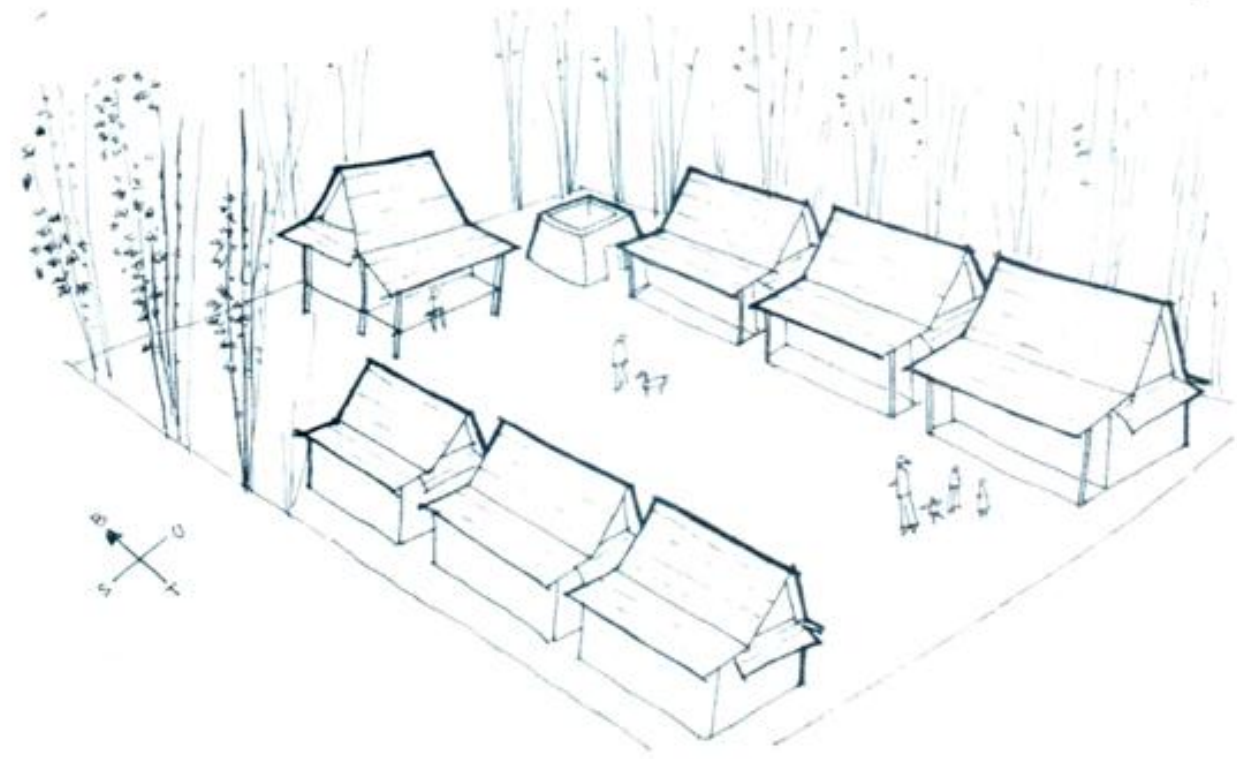

Gambar 1: Pola Susunan Tanean Lanjang (Sumber: Maulidi, 2010)

Ruang memiliki tiga dimensi dimana obyek dan peristiwa berada. Ruang memiliki posisi serta arah yang relatif, terutama bila suatu bagian dari daerah tersebut dirancang sedemikian rupa untuk tujuan tertentu. Ruang merupakan wadah dari aktivitas-aktivitas manusia, baik aktivitas untuk kebutuhan fisik maupun emosi manusia. Ruang adalah sistem lingkungan buatan yang terkecil dan digunakan manusia dalam melaksanakan aktivitasnya sehari-hari (Haryadi \& Setiawan : 1995).

Definisi ruang menurut Ching (2008) adalah sesuatu yang melingkupi obyek yang terdiri dari elemen titik, garis, bidang dan volume yang dapat dirasakan kehadirannya. Menurut Johara T. Jayadinata dalam Arimbawa \& Santhyasa
(2010), ruang merupakan tempat interaksi masyarakat dalam kaitannya dengan kehidupan sosial dan kemasyarakatannya. Dalam hal ini ruang dapat dikatakan sebagai wadah untuk menyalurkan berbagai aktivitas sosial, ekonomi dan budaya masyarakatnya.

Haryadi \& Setiawan (1995) memaknai konsepsi mengenai ruang melalui tiga pendekatan, yaitu antara lain: (1) Pendekatan ekologis, memandang ruang sebagai satu kesatuan sistem yang komponen-komponen pembentuk ruang saling berkaitan satu sama lain dan saling berhubungan; (2) Pendekatan fungsional dan ekonomi, memandang ruang sebagai wadah fungsional untuk kegiatan manusia; (3) Pendekatan sosio politis, memandang ruang sebagai sarana kekuasaan 
sehingga dapat menimbulkan konflikkonflik atar kelompok.

Unsur pembentuk ruang dalam Wahid dan Alamsyah (2013) terdiri dari: (1) Lantai (the base plane). Lantai merupakan komponen penting dalam suatu ruang. Kekuatan, tekstur, visual dan kepadatan material lantai akan mempengaruhi aktivitas manusia dalam memanfaatkan ruang; (2) Dinding / pembatas (the vertical space devider). Dinding merupakan elemen pembatas ruang yang merupakan satu kesatuan dengan lantai; (3) Atap (the overhead plane). Atap mempengaruhi bentuk bangunan dan merupakan pelindung utama dari kondisi iklim. Kualitas material dan visual akan mempengaruhi atap sebagai salah satu unsur pembentuk ruang.

Hermanto (2008) menyebutkan bahwa karakteristik ruang meliputi: (1) Bentuk Ruang. Ruang selalu mempunyai bentuk. Menurut Zeizel (1991) bentuk merupakan bagian dari suatu keadaan yang dapat merubah pola interaksi manusia. Bentuk memberikan pengaruh utama secara visual dan hubungan persepsi jika diinginkan, bentuk dapat memberikan petunjuk yang menganggap area dalam satu bagian menjadi bagian lain yang terpisah; (2) Orientasi Ruang. Menurut Zeizel (1991), penggunaan ruang untuk suatu kegiatan tertentu seringkali terkait dengan bagaimana ruang tersebut ditemukan. Orientasi ruang dapat memberikan peluang agar ruang tersebut mudah ditemukan, dilihat, diawasi, dan dicapai; (3) Ukuran Ruang. Hubungan kedekatan sosial antara manusia menurut Zeizel (dalam Hermanto) dapat terlihat sebagai jarak sosial. Jarak tersebut diaransemen oleh ukuran ruang. Pada ruang dengan ukuran lebih besar, orang lebih mudah melakukan pemisahan diri, sedangkan ruang dengan ukuran lebih kecil orang-orang merasa berada dalam suatu kebersamaan; (4) Pembatas Ruang (Barriers). Zeizel (1991) menyatakan bahwa pembatas ruang adalah semua elemen fisik yang dapat mempersatukan atau memisahkan manusia dalam suatu dimensi. Pembatas juga menjelaskan perbedaan kepemilikan antar suatu Langkau Betang: Vol. 2, No.1 (ISSN 2355-2484) tempat yang diperbolehkan dan yang dilarang. Dengan demikian unsur pembatas ini sangat menentukan pengambilan keputusan tentang ruang yang akan digunakan. Elemen fisik yang dimaksud dapat berupa pagar, dinding, tanaman, atau fasilitas umum. Tiap elemen memiliki sifat yang berbeda, oleh karena itu fungsi kegiatan yang terjadi selalu akan menyesuaikan dengan kondisi yang ada; (5) Komponen Ruang. Di dalam ruang terdapat berbagai komponen yang memiliki kekuatan sebagai penarik atau magnet berlangsungnya suatu fungsi kegiatan. Akibat dari komponen tersebut menimbulkan fungsi kegiatan lain yang disebut sebagai kegiatan bawaan, sehingga akan meningkatkan frekuensi dan variasi kegiatan di ruang tersebut; (6) Kondisi Ruang. Sarwono (1992) menyebutkan bahwa kondisi ruang terkait dengan temperatur, polusi udara dan kebisingan. Pada ruang dengan suhu atau kebisingan yang berlebihan, manusia cenderung menghindar, sebaliknya manusia akan memanfaatkan ruang bila kondisinya menunjukkan situasi yang teduh, nyaman, dan tidak polusif.

Dalam perjalanannya pembahasan mengenai ruang tidak lagi membuat keduanya sebagai sebuah dikotomi barat dan timur, dari sini paling tidak kita tahu bahwa pada awalnya ada pemahaman yang sangat berbeda tentang ruang. Disatukannya konsep ruang menurut pandangan barat dan timur memberikan penjelasan pada kita tentang properti ruang, bahwa ruang hadir dengan atau tanpa kejelasan fisik. Eksistensi ruang dipahami dengan kelengkapan properti teritori, skala, orientasi dan makna. Dari pemahaman ruang tersebut kemudian berkembangkanlah konsep territorial, konsep makna, skala dan orientasi.

\section{Metode}

Metode yang digunakan dalam penelitian ini adalah metode penelitian deskriptif kualitatif. Data diperoleh dengan melalui observasi langsung di lapangan dan wawancara. Observasi di lapangan dilakukan dengan mengacu pada karakteristik ruang yang meliputi bentuk Hal. 13 
ruang, ukuran ruang, pembatas ruang (barriers), dan komponen ruang. Dari hasil observasi terhadap karakteristik ruang pada rumah tradisional Tanean Lanjhang di lokasi studi.

\section{Pembahasan}

Tanean Lanjhang merupakan bentuk rumah tradisional Madura yang memiliki komponen-komponen yang di antaranya adalah Langghar (Musholla), Rumah Utama yang diikuti rumah-rumah lainnya yang pada umumnya berderet dari Barat ke Timur, sesuai dengan urutan dalam keluarga, Dapur, Kandang, dan Tanean (pekarangan).

Lokasi Studi bertepatan di Desa Bandang Laok, Kecamatan Kokop, Kabupaten Bangkalan, Madura yang difokuskan pada Dusun Baktalbak. Di Dusun Baktalbak sendiri, masih banyak ditemukan rumah tradisional Tanean Lanjhang. Dengan masih tersedianya lahan yang masih luas, tentu saja sangat mendukung untuk membangun rumah dengan tipe Tanean Lanjhang.
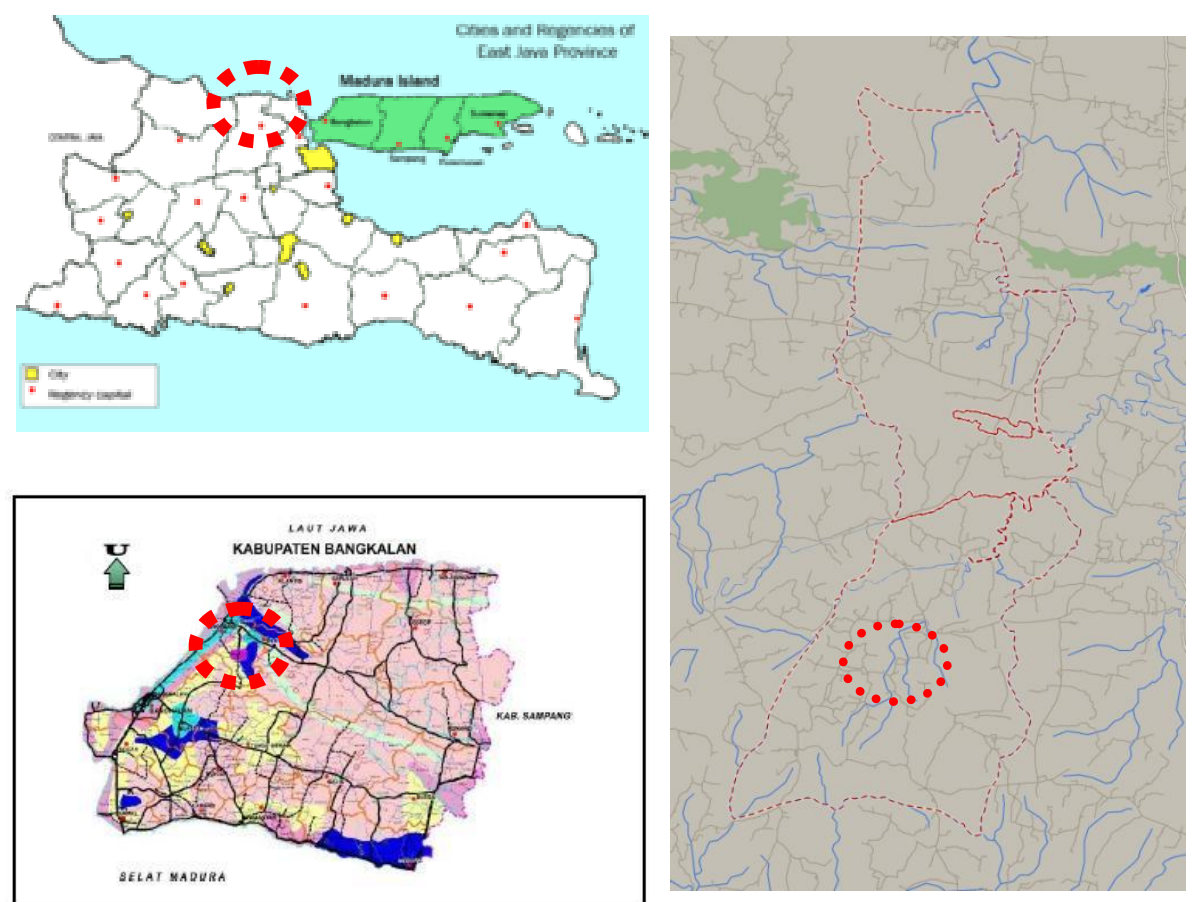

Gambar 2: Pulau Madura di Provinsi Jawa Timur (Gambar atas-kiri), Kabupaten Bangkalan (Gambar bawah - kiri) dan Lokasi Desa Bandang Laok, Kecamatan Kokop, Kabupaten Bangkalan, Madura (Gambar kanan) Sumber: Bangkalan Dalam Angka, 2012 


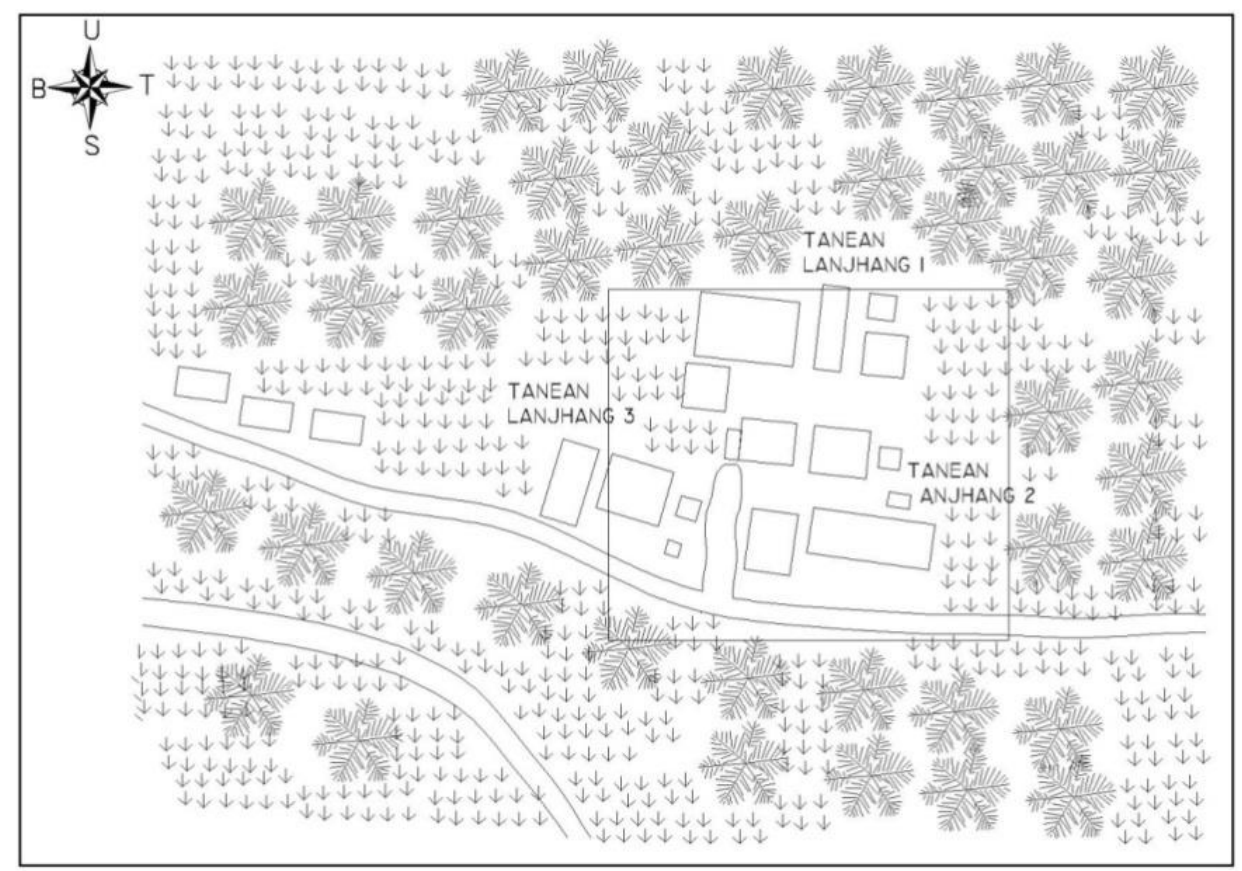

Gambar 3: Site plan Lokasi Tanean Lanjhang 1, Tanean Lanjhang 2, dan Tanean Lanjhang 3. Sumber: Olah Pribadi, 2014

Terdapat tiga kelompok Tanean Lanjhang yang akan dibahas, dimana terdapat hubungan kekerabatan antara pemilik tanean yang satu dengan yang lainnya. Pada hubungan kekerabatan tersebut, menjelaskan tentang 3 (tiga) kelompok Tanean Lanjhang berikut: (1) Kelompok Tanean Lanjhang 1, terdiri dari 5 (lima) rumah utama yang ditempati oleh Ibu Rosyidah (Keluarga Besar), Ibu Astamah (Sendiri), Ibu Nursilah (Sendiri), Ibu Samian (Keluarga Besar), dan lbu
Zahroh (Keluarga Besar); (2) Kelompok Tanean Lanjhang 2, terdiri dari 1 (satu) rumah utama yang ditempati oleh Bapak Ahmad dan keluarga; dan (3) Kelompok Tanean Lanjhang 3, terdiri dari 1 (satu) rumah utama yang ditempati oleh lbu Ruqoyah dan keluarga.

Secara umum, kondisi Tanean Lanjhang 1, Tanean Lanjhang 2 dan Tanean Lanjhang 3 dapat dilihat pada tabel berikut: 
Tabel 1: Kondisi umum Tanean Lanjhang 1, Tanean Lanjhang 2, dan Tanean Lanjhang 3

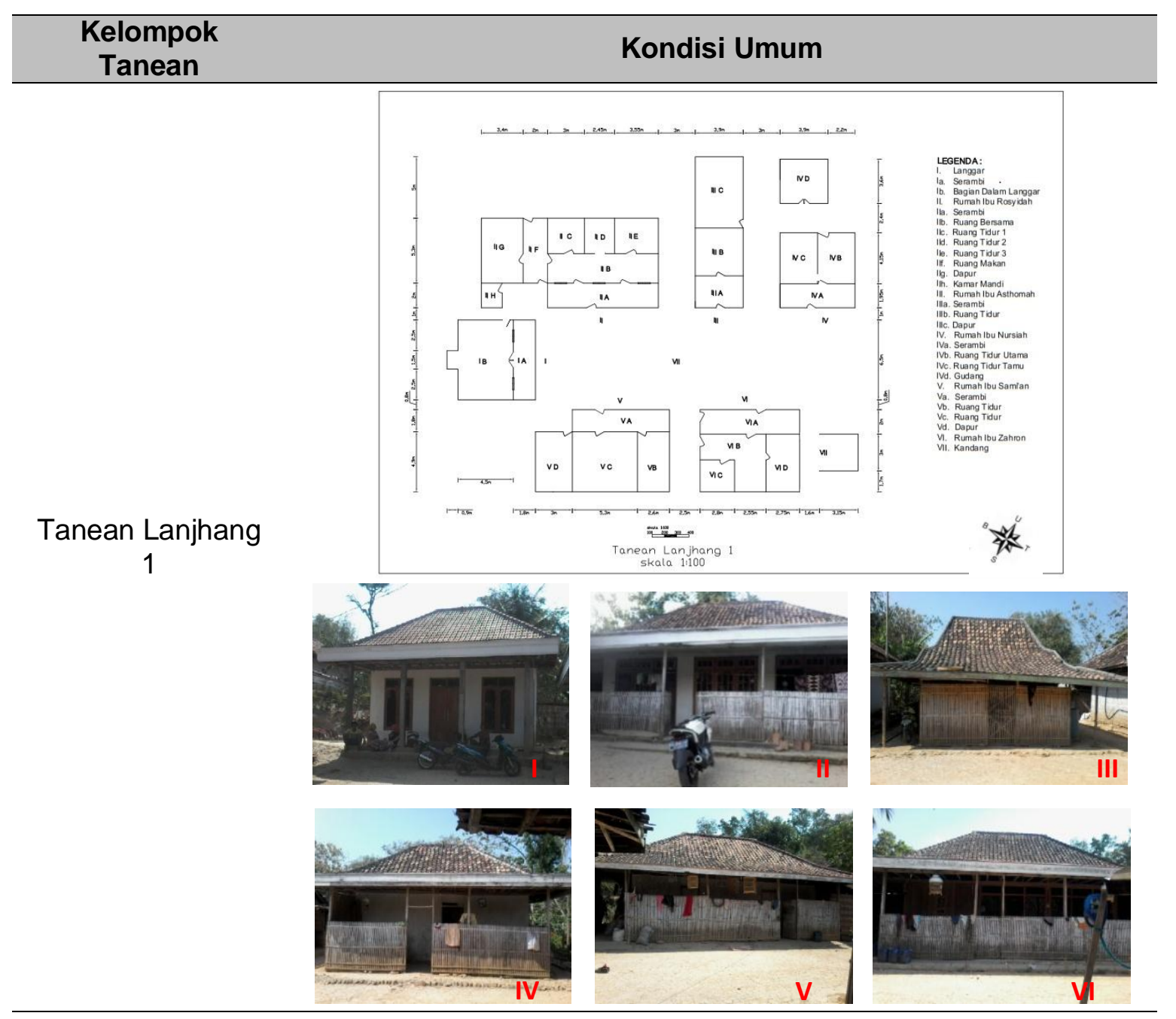

Tanean Lanjhang 2

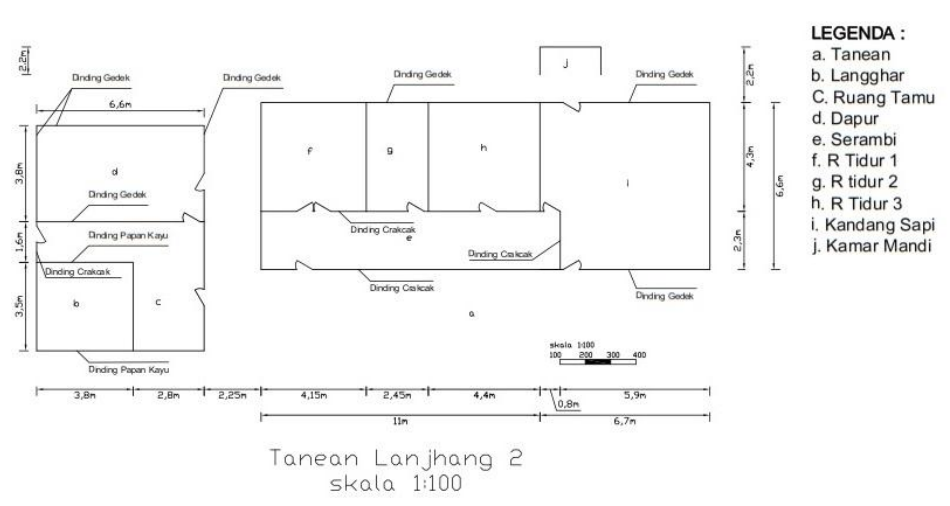

次 

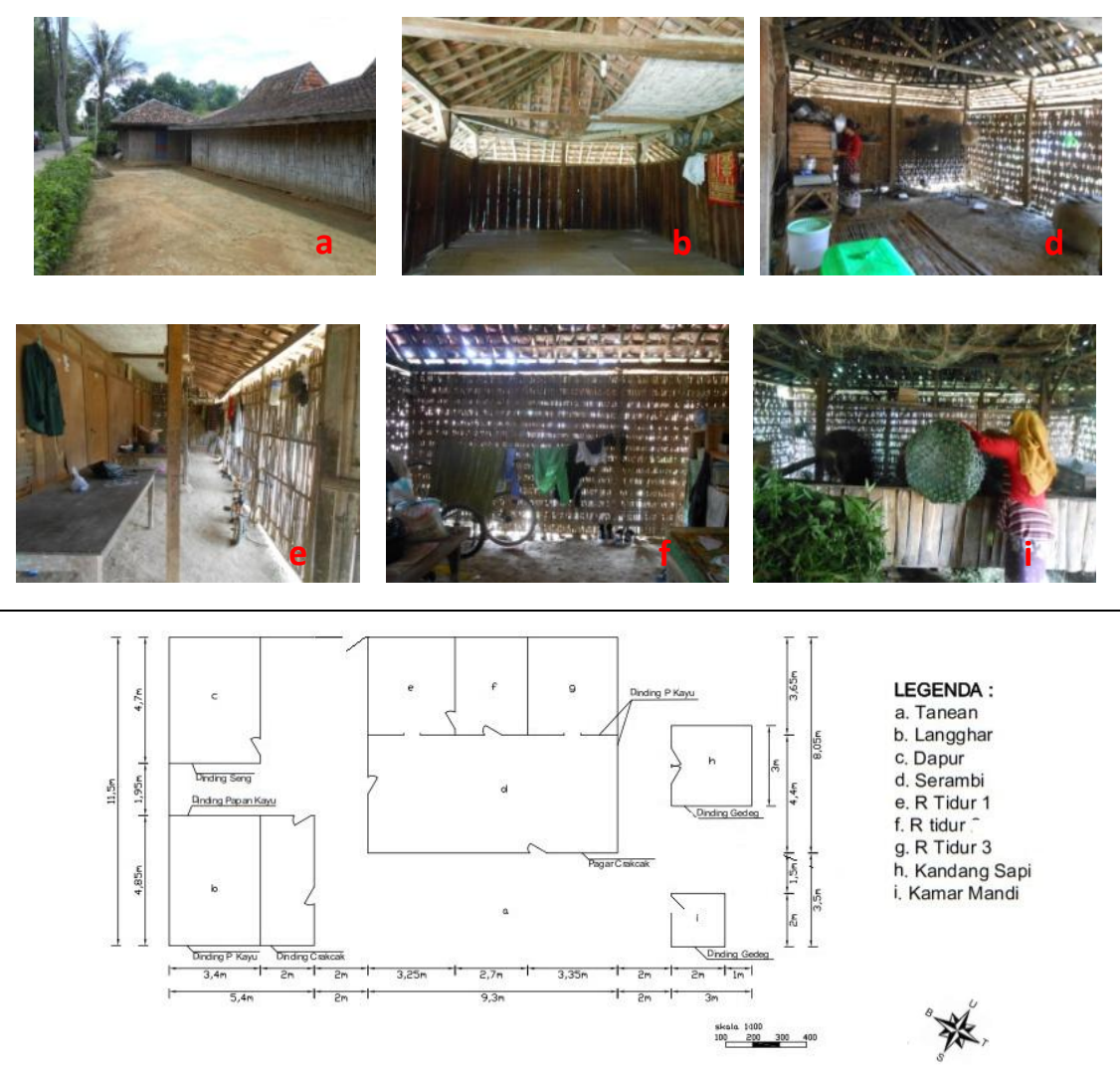

Tanean Lanjhang 3 skala $1: 100$

\section{Tanean Lanjhang}

3
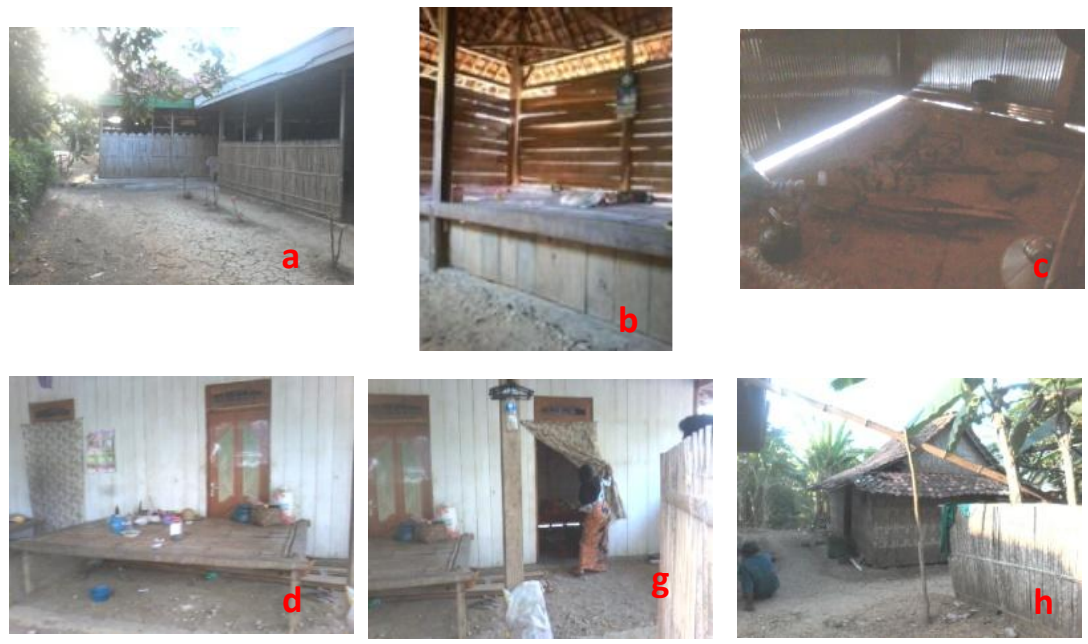

Sumber: Olah Pribadi, 2014

Berdasarkan Hermanto (2008) karakteristik ruang yang akan menjadi dasar pada pembahasan ini hanya 4 (empat) yaitu bentuk \& ukuran ruang, pembatas ruang, dan komponen ruang.
Karakteristik ruang pada Tanean Lanjhang 1, Tanean Lanjhang 2, dan Tanean Lanjhang 3 dapat dilihat pada tabel berikut ini. 
Tabel 2: Karakteristik Ruang pada Tanean Lanjhang 1, Tanean Lanjhang 2, dan Tanean Lanjhang 3

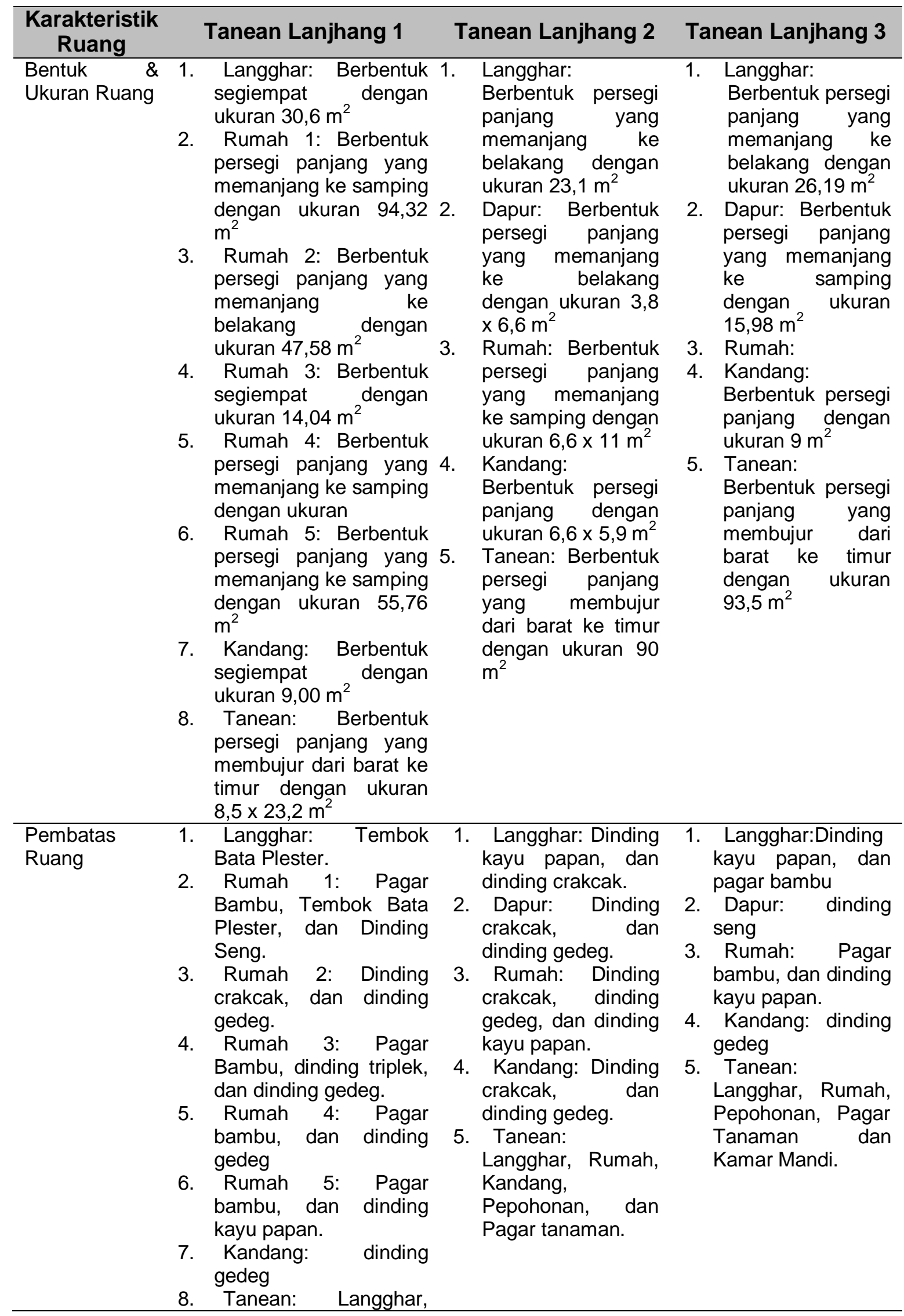




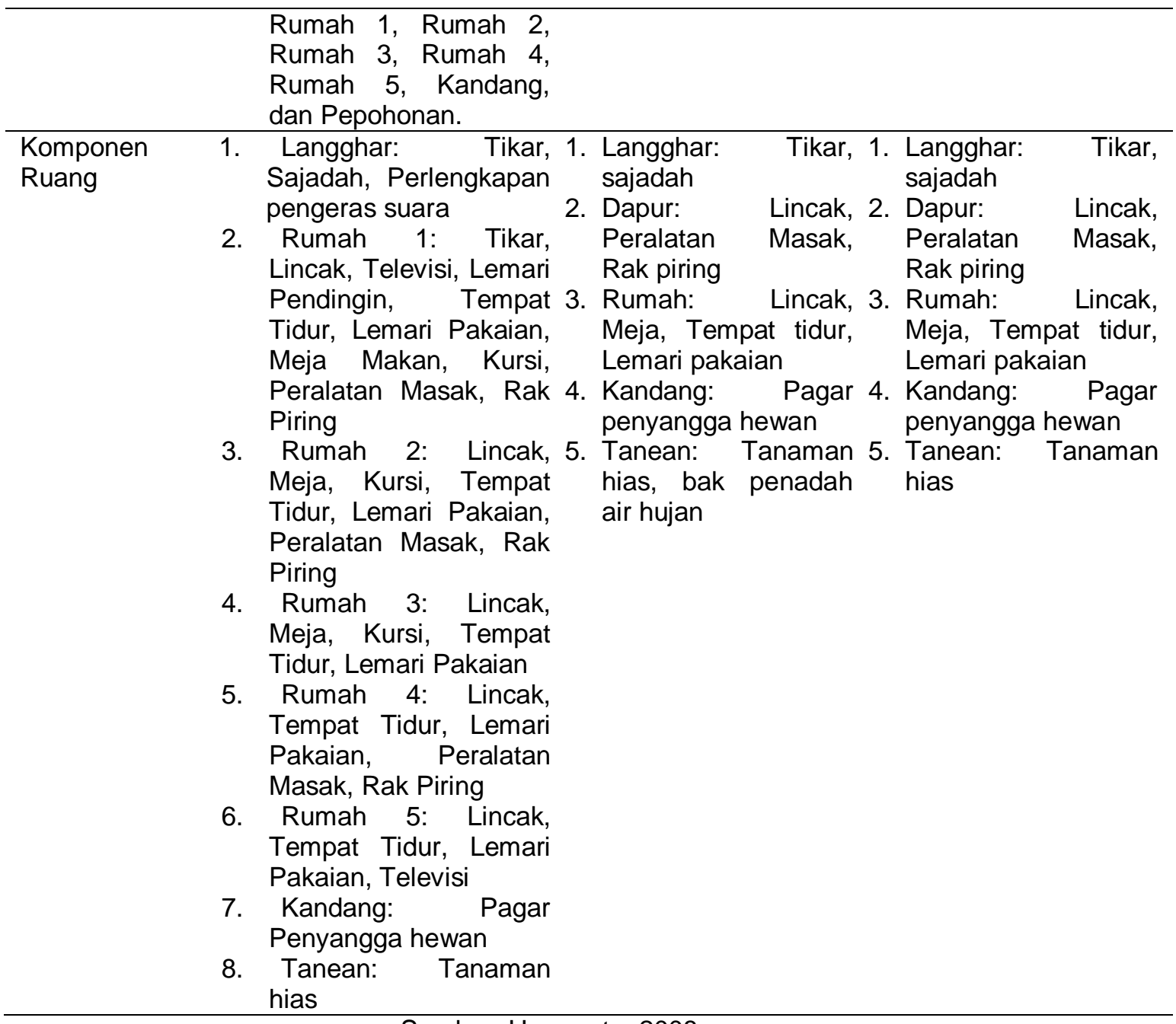

Sumber: Hermanto, 2008

Hasil analisis berdasarkan identifikasi dari karakteritik ruang antara Tanean Lanjhang 1, Tanean Lanjhang 2, dan Tanean Lanjhang 3, adalah sebagai berikut:

1. Terdapat perbedaan antara Tanean Lanjhang 1, Tanean Lanjhang 2, dan Tanean Lanjhang 3. Dimana pada Tanean Lanjhang 1 susunannya terdiri dari beberapa rumah hunian yang dihuni oleh beberapa kepala keluarga. Sedangkan pada Tanean Lanjhang 2 dan Tanean Lanjhang 3 susunannya hanya terdiri dari 1 rumah hunian yang hanya dihuni oleh 1 kepala keluarga saja. Hal ini disebabkan oleh keterbatasan lahan untuk mendirikan rumah hunian baru, sehingga keluarga baru/muda harus membuat rumah hunian lain dengan pola Tanean
Lanjhang juga, yaitu pada Tanean Lanjhang 2 dan Tanean Lanjhang 3.

2. Karakteristik ruang pada ke-tiga Tanean Lanjang dapat dilihat pada pembahasan berikut:

a. Sebagian besar bentuk ruang pada Tanean Lanjhang 1, Tanean Lanjhang 2, dan Tanean Lanjhang 3 adalah segiempat dan persegipanjang dengan ukuran ruang yang beragam. Hal ini menunjukkan bahwa sebagian besar bentuk ruang pada tiap Tanean Lanjhang memiliki bentuk yang sama yaitu segiempat dan persegipanjang, sesuai dengan fungsi dan kegunaannya.

b. Pembatas ruang pada Tanean Lanjhang 1, Tanean Lanjhang 2, dan Tanean Lanjhang 3 di antaranya adalah: tembok bata Hal. 19 
plester, dinding seng, dinding papan kayu, dinding gedeg, dinding crakcak, dan pagar bambu. $\mathrm{Hal}$ ini menunjukkan tingkat perekonomian yang berbeda di antara pemilik rumah yang satu dengan yang lain. Dimana pemilik rumah dengan pembatas ruang berupa tembok bata plester dan dinding seng memiliki tingkat perekonomian yang lebih tinggi dibandingkan dengan pemilik rumah dengan pembatas ruang yang berupa papan kayu, gedeg, dan crakcak. Dimana papan kayu dan juga gedeg dan crakcak yang berbahan dasar kayu dan bambu, mudah untuk didapatkan di sekitar lokasi tersebut sehingga tidak perlu mengeluarkan banyak biaya.

c. Komponen ruang pada Tanean Lanjhang 1, Tanean Lanjhang 2, dan Tanean Lanjhang 3 di antaranya adalah: Tikar, Lincak, Televisi, Lemari Pendingin, Tempat Tidur, Lemari Pakaian, Meja Makan, Kursi, Peralatan Masak, dan Rak Piring. Sama halnya dengan karakteristik ruang berupa pembatas ruang, komponenkomponen ruang tersebut juga menunjukkan tingkat perekonomian yang berbeda di antara pemilik rumah yang satu dengan yang lain. Dimana pemilik rumah dengan televisi dan lemari pendingin memiliki tingkat perekonomian yang lebih tinggi dibandingkan dengan pemilik rumah yang hanya terdapat Tikar, Lincak, Tempat Tidur, Lemari Pakaian, Meja Makan, Kursi, Peralatan Masak, dan Rak Piring pada rumahnya.

\section{Kesimpulan dan Saran}

Berdasarkan hasil identifikasi dan analisis terhadap karakteristik ruang pada Tanean Lanjhang 1, Tanean Lanjhang 2, dan Tanean Lanjhang 3 yang terdapat di Dusun Baktalbak menunjukkan bahwa pola Tanean Lanjhang dengan 1 rumah utama saja (yang ditunjukkan oleh Tanean Lanjhang 2 dan Tanean Lanjhang 3) disebabkan oleh keterbatasan lahan untuk mendirikan rumah hunian baru, sehingga keluarga baru/muda harus membuat rumah hunian lain dengan pola Tanean Lanjhang juga. Selain itu terdapat persamaan bentuk ruang dengan ukuran ruang yang bervariasi, sesuai dengan fungsi dan kegunaan. Sementara itu, perbedaan pembatas ruang dan komponen ruang menunjukkan tingkat perekonomian yang berbeda.

\section{Daftar Pustaka}

Arimbawa, W., Santhyasa, I Komang Gede. 2010. Perspektif Ruang Sebagai Entitas Budaya Lokal: Orientasi Simbolik Ruang Masyarakat Tradisional Desa Adat Penglipuran, Bangli-Bali. Local Wisdom Jurnal IImiah Online

Departemen Pendidikan dan Kebudayaan. 1982. Sistem Kesatuan Hidup Setempat Daerah Jawa Timur. Jakarta: Depertemen Pendidikan dan Kebudayaan.

Haryadi., Setiawan, B .1995, Arsitektur Lingkungan dan Perilaku. Dirjen Dikti, Depdikbud RI.

Hermanto, H. 2008. Faktor-faktor yang Berpengaruh terhadap Perubahan Fungsi Ruang di Serambi Pasar Induk Wonosobo. Universitas Diponegoro. Semarang

Lefebvre, Henry. 1991. The Production of Space. Blackwell Publishing. United Kingdom.

Maulidi, Chairul. 2010, Harmonisasi ruang, alam dan budaya tradisional madura: sebuah konsep adaptasi lingkungan perkotaan terhadap dampak perubahan iklim. Program Studi Rancang Kota Sekolah Arsitektur, Perencanaan dan Pengembangan Kebijakan Institut Teknologi Bandung

Rapoport, Amos, 1969, House Form and Culture. Englewood Cliffs,N.J. Prentice-Hall, Inc.

Sarwono, Sarlito Wirawan. 1992. Psikologi Lingkungan. PT Gramedia, Jakarta 
Tulistyantoro, Lintu. 2005. Makna Ruang Pada Tanean Lanjang Di Madura, Dimensi Interior, Vol. 3, No. 2: 137 152.

Wahid, J., Alamsyah, B. 2013. Teori Arsitektur; Suatu Kajian Perbedaan Pemahaman Teori Barat dan Timur. Graha IImu, Yogyakarta

Wiryoprawiro, Zein, M. 1986. Arsitektur Tradisional Madura - Sumenep. Laboratorium Arsitektur Tradisional Fakultas Teknik Sipil dan Perencanaan Institut Teknologi Sepuluh November, Surabaya. 